\title{
A liderança na gestão das escolas: contributos de análise organizacional
}

\section{Leadership in school management: contributions from organizational analysis El liderazgo en la gestión de las escuelas: aportes de análisis organizacional \\ JORGE ADELINO COSTA PATRÍCIA CASTANHEIRA}

\begin{abstract}
Resumo: A liderança constitui um tema cada vez mais presente nas abordagens que elegem a análise organizacional e a gestão das escolas como centros de interesse. Tratando-se de um fenómeno complexo, o seu estudo não pode ser isolado de outras vertentes básicas para a compreensão da escola, tais como os modelos de administração e gestão e os pressupostos teórico-concetuais das perspetivas organizacionais que enquadram o seu funcionamento. Neste artigo procuramos, num primeiro momento, situar a evolução histórica das conceções sobre liderança no contexto das teorias organizacionais e, numa segunda etapa, identificar algumas das principais dimensões que nos parecem prementes a uma certa peculiaridade do exercício da liderança nas escolas. Como principais objetivos deste trabalho pretendemos, por um lado, contribuir para o incremento da investigação num domínio inerente à gestão das escolas ao qual nem sempre foi dada a devida atenção e, por outro, alertar para a necessidade de se incrementar, em termos de políticas educativas, programas de formação especializada para os gestores escolares que elejam este domínio como conteúdo estratégico.
\end{abstract}

Palavras chave: Gestão das escolas; liderança escolar; análise organizacional da escola.

Abstract: School leadership is a recurrent theme in the approaches that focus on organizational analysis and school management. As a complex phenomenon, the study of school leadership cannot be isolated from other basic underpinnings of the understanding of school, such as models for administration and management and the theoretic-conceptual frameworks of the organizational perspectives that frame its' functioning. In this paper, we aim at, in a first instance, mapping the historical evolution of the theories on school leadership in the context of organizational theories. In a second part of the paper we will identify some of the main dimensions that are particularly pressing in the exercise of school leadership in schools. As main objectives of our work we want to, on one hand, contribute to the broadening of the study of a particular domain of school management that has been somewhat neglected and, on the other hand, to raise awareness, in what concerns educational policies, for the need to implement programs of specialized training for school managers that choose school leadership as a strategic content. 
Keywords: School management; school leadership; school organizational analysis.

Resumen: El liderazgo escolar es un tema cada vez más presente en los enfoques que eligen la análisis organizacional y la gestión de las escuelas como centros de interés. Como se trata de un fenómeno complejo, su estudio no se puede aislar de otros aspectos básicos para la comprensión de la escuela, tales como los modelos de administración y gestión y supuestos teóricos y conceptuáis de las perspectivas organizativas que enmarcan su funcionamiento. En este artículo, en primer lugar, intentamos situar el desarrollo histórico de los conceptos de liderazgo en el contexto de las teorías de la organización y, en una segunda etapa, identificar algunas de las dimensiones clave que subyacen a una cierta peculiaridad del ejercicio del liderazgo en las escuelas. Como principales objetivos de este trabajo queremos, por un lado, contribuir al aumento de la investigación en la gestión escolar en este dominio inherente a lo cual ni siempre se presta la debida atención y, en segundo lugar, llamar la atención sobre la necesidad de aumentar, en lo que concierne la política educativa, programas de capacitación especializados para administradores escolares que elijan el liderazgo escolar como contenido estratégico.

Palabras clave: Gestión escolar; liderazgo escolar; análisis organizacional de la escuela.

\section{INTRODUÇÃO}

A liderança tem constituído um dos objetos de estudo privilegiados de várias ciências sociais e humanas, ocupando um lugar de destaque na investigação e na reflexão sobre as organizações, com destaque para as questões da sua gestão. Trata-se, por isso, de um daqueles conceitos relativamente aos quais se tem dedicado maior número de páginas, quer estejamos no quadro dos estudos sobre os fenómenos sociais, em geral, quer no que diz respeito à análise dos comportamentos humanos, em particular ${ }^{1}$.

Se, no contexto específico da análise educacional, designadamente no campo da pedagogia, a questão da liderança esteve sempre implícita, no que se refere à análise organizacional das escolas, em países como Portugal e Brasil, o assunto está longe da centralidade que outros colegas, noutros contextos geográficos, lhe atribuem. A propósito, já no início do milénio, Bush e Coleman referiam-se à liderança e à gestão estratégica como "o coração do debate educacional" (BUSH; COLEMAN, 2000). Constata-se, portanto, a atribuição progressiva da

\footnotetext{
${ }^{1}$ A problemática da gestão e liderança das escolas é o tema de investigação a que os autores deste trabalho têm dedicado mais atenção nos últimos anos, constituindo o presente artigo, em particular no que diz respeito à sua primeira parte, a atualização de um outro trabalho divulgado no início do presente milénio (COSTA, 2000).
} 
importância da liderança para a melhoria da escola e para a aprendizagem dos alunos em vários estudos (veja-se, por exemplo, BUSH; COLEMAM, 2000; CASTANHEIRA, 2014; CASTANHEIRA; COSTA, 2011; DAY et al., 2008; HARRIS; CHAPMAN, 2002; LEITHWOOD et al. 2006; PASHIARDIS, 2014; SPILLANE et al., 1999). Porém, mesmo assim, "é seguro afirmar que a natureza da liderança escolar eficaz continua a ser muito mais uma caixa negra do que aquilo que gostaríamos de admitir" (LEITHWOOD; JANTZI, 2005, p. 202).

A perspetiva que nos norteia neste texto é a de nos situarmos no campo da análise organizacional para olharmos a liderança no contexto das teorias da administração e da análise organizacional. Assumimos, portanto, o pressuposto de que a liderança não constituiu um campo neutro, facilmente manipulável por qualquer receituário tecnocrático do tipo take away (com que vários textos sobre a temática diariamente nos brindam), mas que se trata de um fenómeno mais complexo cuja explicação carece de um enfoque organizacional.

Procuraremos, então, numa primeira parte, passar em revista as conceções que a literatura sobre a liderança nos tem proposto, visualizando-as através das lentes de várias teorias organizacionais, para continuarmos, numa segunda parte, com um olhar centrado na identificação de algumas das principais dimensões que nos parecem ser de valorizar no campo específico das organizações escolares.

\section{LIDERANÇA E TEORIAS ORGANIZACIONAIS NUM OLHAR CRUZADO}

Neste ponto centramos a nossa reflexão em torno de três grandes concepções de liderança que classificamos como a visão mecanicista, a visão cultural e a visão ambigua. Estas conceções, não obstante a sua contextualização e sequencialidade histórica, não são, nem completamente estanques ou mutuamente exclusivas, nem sequer, pelo facto de terem surgido em determinada época histórica, sucumbiram à evolução teórica posterior, mas mantêm, ainda hoje, seguidores mais ou menos fiéis. Na realidade, Rost (1991), ao analisar 221 definições de liderança numa revisão de literatura que se foca em trabalhos publicados entre 1920 e o início dos anos 90 do seculo XX, refere que as diferentes conceções de liderança que foram surgindo ao longo do século passado refletem a evolução do campo e a sua interligação com os acontecimentos mais marcantes da história. 


\section{VISÃO MECANICISTA DA LIDERANÇA}

De acordo com Bryman² (1996, p. 276-277), a conceção de liderança que suporta a teoria e a investigação desenvolvida desde os anos 40 (época que marca o início das preocupações académicas sobre a temática) até ao início dos anos 80 pode alinhar-se à volta de três conceitos: influência, grupo, objetivos. $\mathrm{O}$ autor apresenta como ilustração para esta conceção de liderança a definição proposta por Stogdill, em 1950: "A liderança pode ser vista como processo (ato) de influenciar as atividades de um grupo organizado nos seus esforços para atingir determinados objetivos" (BRYMAN, 1996, p. 276).

Neste sentido, a liderança foi concebida, durante este período de quatro décadas, como o ato de influenciar um grupo para atingir determinados objetivos. Trata-se de uma visão hierárquica, unidirecional e sequencial da liderança que, de certa maneira, acompanha as várias concepções e teorias organizacionais presentes nesta época e que apelidamos de visão mecanicista da liderança, já que esta parece ser entendida como uma acção lógica, mecânica, automática, desencadeada por alguém que, detentor de certos predicados, leva outros a atingirem determinados resultados pré-definidos.

Não será difícil encontrar um suporte mais abrangente para este posicionamento se invocarmos aquilo a que alguns chamam paradigma positivista ou paradigma racional-tecnológico (SÁEZ, 1989) no âmbito do qual se procura compreender a realidade, neste caso, a realidade social, em termos de causalidade linear. De acordo com estes pressupostos, o objetivo central do conhecimento científico consistirá, não só em explicar a realidade, mas também em prescrevêla, procurando identificar-se, de acordo com uma relação mecânica causa-efeito, os fenómenos e as características que os tornarão eficazes.

Em termos de modelos organizacionais, poderemos situar a visão mecanicista da liderança no quadro dos modelos formais de Bush, dos modelos racionais de Ellstrom, do modelo tradicional (ou da racionalidade técnica) de England, do modelo estrutural de Bolman e Deal, para citar alguns dos mais conhecidos (COSTA, 2003; CASTANHEIRA, 2010). Numa leitura mais particularizada das teorias da administração, a visão mecanicista da liderança poderá ser equacionada no quadro de um vasto leque de propostas que vão desde as teorias clássicas (de Taylor, Fayol e seguidores), passando pela teoria das relações humanas e teorias comportamentais, até às perspetivas sistémicas e da contingência.

Porém, esta visão mecanicista da liderança foi alvo de variações significativas no decorrer das quatro décadas mencionadas antes e, daí, a sua

\footnotetext{
${ }^{2}$ Consideramos o texto de Alan Bryman, Leadership in Organizations (1996), um excelente trabalho de síntese sobre esta temática e seguimo-lo de perto na estruturação global da primeira parte deste trabalho.
} 
subdivisão em três orientações distintas que ilustramos com os conceitos de líder nato, líder treinado e líder ajustável.

\section{O LÍDER NATO}

A ideia de que se nasce líder é aquela que protagoniza os primórdios das conceções e da investigação sobre a presente problemática: ou seja, estamos a reportar-nos à conhecida teoria dos traços e aos vários desenvolvimentos de que a mesma foi alvo no decorrer dos anos 40. Os seus defensores partem do pressuposto de que há determinadas características próprias dos líderes, características pessoais (com um grau significativo de inatismo), e que a tarefa prioritária, no caso dos investigadores, consistirá em identificar essas características, esses traços e, no caso dos responsáveis organizacionais/ empresariais, será a de selecionar os indivíduos que as possuam para ocupar os lugares-chave (de topo) das organizações.

Vários estudos se dedicaram à conquista deste desiderato. Procuraram os traços físicos (peso, altura, aparência), os traços de personalidade, as competências particulares como a inteligência ou a fluência do discurso, na tentativa de identificar as características pessoais (REGO, 1997) dos grandes bomens. Idalberto Chiavenato aponta como influência para esta perspetiva da liderança a chamada "teoria do grande homem", defendida por Carlyle no início do século, precisamente em 1910, com a publicação do livro Lectures on Heroes, Hero-Workship, and the Heroic in History, obra na qual este autor defende a ideia de que "o progresso do mundo foi produto das realizações pessoais de alguns grandes homens que dominam a história da humanidade" (CHIAVENATO, 1983: 127).

Não obstante as questões da liderança surgirem na reflexão organizacional a partir dos anos 30 - com a teoria das relaçôes humanas e a "descoberta do factor humano" nas organizações (COSTA, 2003, p. 57-61) — não constituindo por isso preocupação visível das teorias anteriores (as chamadas clássicas), poderíamos, todavia, estabelecer aqui um certo paralelismo entre a visão do líder nato e o modelo que Taylor apresenta, no início do século, para a "seleção científica" do trabalhador:

Em face da seleção científica do trabalhador, dos 75 carregadores de barras de ferro, só aproximadamente um em oito era capaz fisicamente de carregar 47,5 toneladas por dia. Com a melhor das intenções, os outros sete eram homens fisicamente inaptos para trabalho nesse ritmo. Ora, o único homem entre oito, capaz de fazer o trabalho, não tinha, em nenhum sentido, características de superioridade sobre os outros. Apenas era um homem tipo bovino - espécime difícil de encontrar e, assim, muito valorizado. Era tão estúpido quanto incapaz 
de realizar a maior parte dos trabalhos pesados. A selecção, então, não consistiu em achar homens extraordinários, mas simplesmente em escolher entre homens comuns os poucos especialmente apropriados para o tipo de trabalho em vista (TAYLOR, 1990, p. 54-55).

Esta perspetiva tayloriana da seleção dos trabalhadores com base nas suas características individuais, neste caso físicas, bem como toda uma conceção do indivíduo enquanto ser isolado, atomizado, mecanicamente encadeado, não parece andar muito longe da metáfora do líder nato, também este imbuído de determinados predicados pessoais (naturais), os quais "automaticamente" levarão a desempenhos previstos e eficazes.

A procura dos "traços mágicos da personalidade", no dizer de Fiedler (1990, p. 417) - um intento que permitisse predizer a liderança eficaz — tem também algum paralelismo, no quadro de uma conceção inata dos atributos pessoais, nos contextos educacionais e pedagógicos. Ainda que não seja objeto particular da presente análise, invoque-se, a propósito, as perspetivas de sucesso educativo e profissional como as que estão presentes na teoria dos dons, na teoria da meritocracia, ou mesmo, no caso da formação de professores, nas conceções inatistas do bom professor que, segundo alguns apologistas, dispensam formação e preparação pedagógica e que se bastam com a formação da especialidade (como aqui e ali ainda se sussurra pelos campus académicos).

A decadência da visão do líder nato, certamente devido a todo um conjunto de desenvolvimentos das perspetivas comportamentais neste período, ocorreu a partir dos finais dos anos 40, cedendo-se assim lugar a uma outra visão da liderança, cujo objeto (e objetivo) de estudo passa a ser o comportamento do líder: são as teorias sobre os estilos de liderança.

\section{O LÍDER TREINADO}

Os anos 50 vão marcar um período em que as pesquisas sobre a liderança se dirigem para a identificação dos comportamentos daqueles líderes que asseguram a eficácia do grupo que lideram. Torna-se necessário saber o que o líder faz, a maneira como o faz, como se comporta, ou seja, o seu estilo de liderança. Já não estamos perante um líder nato, mas um líder que pode e deve ser feito: identificadas "as melhores maneiras" de atuação do líder, definidos os seus "comportamentos-padrão" (para voltar a uma terminologia de sabor tayloriano), estes deverão ser objeto de aprendizagem pelos candidatos à liderança. Dá-se início, a partir desta altura, à formação em liderança e à preparação e treino dos líderes. 
Como sabemos, a década de 50 do século XX, é marcada, em termos das teorias organizacionais e administrativas, pelas teorias das relações humanas e seus desenvolvimentos posteriores no âmbito do estudo dos comportamentos humanos nas organizações, constituindo a liderança um assunto central nos trabalhos de vários autores. No caso concreto das teorias dos estilos de liderança, é unânime o reconhecimento dos estudos levados a efeito por um grupo de investigação da Ohio State University - cujo nome de maior relevo é Stogdill - como dos mais importantes nesta área. O seu objetivo foi estudar os comportamentos do líder (os seus estilos de liderança) articulando-os com questões como o desempenho do grupo e a satisfação no trabalho por parte dos subordinados (BRYMAN, 1996, p. 278). Entre as várias propostas conhecidas desta área, não poderemos esquecer, pela divulgação de que têm sido alvo, designadamente no campo educacional e pedagógico, os conhecidos três estilos de liderança de Kurt Lewin: o autocrático, o democrático e o liberal.

Esta perspetiva de entender a liderança, que ilustramos com a imagem do líder treinado, não constituindo certamente uma visão da liderança tão ingénua e mecanicista como a anterior (líder nato), manifesta-se, todavia, ainda como a da procura de um receituário comportamental, de uma cartilha de procedimentos que pretendem transformar os aprendizes de futuros líderes em heróis organizacionais prontos-a-usar (recordemos a vastíssima literatura que muita da imprensa mais apelativa nos propõe: "O líder num minuto"; "Faça-se líder em 10 lições"; "Kit liderança: faça você mesmo, seguindo as instruções";...).

Estamos, porém, perante uma perspetiva que marca uma importante viragem nas conceções da liderança nas organizações, quer pelo reconhecimento da aprendizagem a que estes desempenhos necessitam de estar sujeitos, quer pelos estudos entretanto desenvolvidos sobre os comportamentos dos líderes e sobre os processos de liderança. Todavia, estas orientações não resistirão às conceções sócio-organizacionais dos anos 60: o grau de racionalidade que tradicionalmente é atribuído às organizações começa a ser questionado, a causalidade linear começa a ser posta em causa, surgem os apelos à racionalidade limitada e à relatividade organizacional, a realidade é contingente e duvida-se das intenções do "the one best way".

\section{O LÍDER AJUSTÁVEL}

Que a liderança (também) se aprende e que para isso é necessário conhecer os estilos de liderança parece ser uma das conclusões dos trabalhos sobre a liderança no decorrer dos anos 1950. Porém, a orientação principal que a década seguinte — anos 60 - nos trouxe nesta matéria foi a de que a liderança 
depende dos contextos, das situações, de modo que determinado comportamento do líder pode ser eficaz numa situação mas pode traduzir-se em ineficácia num contexto diferente. São as chamadas teorias situacionais da liderança as quais se encontram enformadas, em termos de análise organizacional, pela teoria da contingência.

A teoria da contingência veio apontar um caminho diferente para o entendimento das organizações (das suas estruturas, dos seus processos de gestão, dos modos de comportamento dos seus membros): em vez do clássico lema "the one best way" (onde se procurava identificar a solução adequada e única), apostase agora no "it all depends". E, assim, tudo depende... dos contextos ambientais, das tecnologias e dos processos utilizados, dos comportamentos dos membros e dos utilizadores, da diversidade das organizações,... ou seja, da relatividade das situações. Como escreveram dois dos nomes mais sonantes desta teoria:

Temos vindo a enfatizar consistentemente a ideia de ajustar a organização ao seu ambiente relevante imediato e às características dos seus contribuintes individuais. Esta abordagem baseia-se na premissa fundamental de que não há um único melhor meio para organizar, mas, pelo contrário, as organizações necessitam de ser sistematicamente adaptadas aos objetivos coletivos e às finalidades humanas individuais (LAWRENCE; LORSCH, 1969, p. 84).

Este princípio básico da teoria da contingência que, segundo estes dois fundadores, consiste em ajustar a organização às características quer do seu ambiente externo quer interno, é também a ideia que percorre as teorias da liderança dos anos 60 - situação que nos leva a falar do lider ajustável. Estas novas orientações colocam agora a tónica na importância que assume cada situação e cada contexto particular para o comportamento do líder, nomeadamente o controlo que este exerce sobre os contextos. É neste quadro que um dos seus seguidores de maior nomeada irá propor um modelo de contingência da liderança e uma teoria dinâmica da liderança baseada no controlo que o líder tem sobre a situação. Estamos a falar de Fiedler e poderemos recordar o seguinte texto do autor:

O conceito chave, aqui apresentado como base para desenvolver uma teoria dinâmica da liderança, é o controlo situacional do líder. Esta é, essencialmente, a dimensão de 'favorabilidade da situação' do modelo da contingência. Espero demonstrar que este conceito nos dá um entendimento do processo de liderança considerável e que também nos permite controlar o processo, isto é, desenvolver um programa de formação em liderança eficaz”(1990, p. 149).

Para além dos estudos de Fiedler sobre os líderes e sobre a necessidade que estes têm de controlar as situações — a favorabilidade da situação — muitas outras propostas e desenvolvimentos teóricos se poderão encontrar nesta linha 
como os que se referem ao ajustamento do comportamento do líder (quer no que concerne à maturidade dos subordinados, quer relativamente às situações de mudança), as teorias dos substitutos do líder, a teoria do caminho-objetivos (REGO, 1997, p. 297 358; TEIXEIRA, 1998, p. 145-153).

As teorias da contingência e a conceção do líder ajustável vieram pôr em causa um modelo rígido de entendimento da liderança — relativizando-o para o tornarem "um pouco mais à medida" — porém e mantendo o nosso posicionamento inicial, continuamos perante uma visão mecanicista da liderança assente nos três vetores antes identificados: a influência, o grupo, os objetivos.

Assim, sem que esta seja uma perspetiva completamente abandonada pelos especialistas da área — quer porque, como refere Bryman, "por vezes a investigação sugere-nos que os fatores situacionais não são sempre tão importantes como seria de esperar" (1996, p. 280), quer porque novos desenvolvimentos teóricos propõem outras explicações para os fenómenos organizacionais e outros modos de gestão — os anos 80 vão mostrar novos caminhos e novos modos de entender a liderança nas organizações.

\section{VISÃO CULTURAL DA LIDERANÇA: O LÍDER COMO GESTOR DE SENTIDO}

A década de 1980 constituiu um período em que a visão mecanicista da liderança, nos moldes em que a temos vindo a encarar, sofreu um profundo abalo.

Globalmente, poderemos dizer que o líder deixa de ser encarado como aquele que conduz, de forma mecânica, hierárquica e prescritiva, o processo de influenciar os outros a atingir objetivos pré-definidos, para começar a ser visto como um gestor de sentido, ou seja, alguém que define a realidade organizacional através da articulação entre uma visão (que é reflexo da maneira como ele define a missão da organização) e os valores que lhe servem de suporte (BRYMAN, 1996, p. 280).

É patente desde o início dos anos 1980 - no quadro de um movimento que ficou conhecido por Nova Liderança — um conjunto de teorizações sobre a liderança assente em pressupostos comuns (embora nem sempre completamente sintonizados), no âmbito do qual encontramos conceções como as da liderança transformacional, em contraste com a liderança transacional (BURNS, 1978; BASS, 1985), da liderança carismática (HOUSE, 1977), da liderança visionária e de outros 
desenvolvimentos que, como refere Bryman (1996, p. 280), surgem simplesmente identificados com o conceito de liderança $a^{3}$.

Colocando as questões da criação e da gestão da cultura no centro da atuação dos líderes e fazendo da dimensão simbólica o mote da sua ação, esta visão da liderança encontra o seu referencial teórico, em termos de análise organizacional, na perspetiva da cultura organizacional. Reportamo-nos aos desenvolvimentos que as teorias organizacionais sofreram a partir dos anos 80 com vários trabalhos que, situados no campo da gestão empresarial, procuravam explicar o sucesso de empresas japonesas (e ocidentais) de sucesso. Entre outros autores, destaque-se os nomes de Deal e Kennedy (1988) e de Peters e Waterman (1987) que apontam como explicação central para o sucesso das empresas analisadas a existência de culturas fortes e de valores partilhados entre os seus membros. Em sintonia com estes pressupostos, um pouco mais tarde, Edgar Schein, articulando a questão da cultura com a da liderança, referia que "a única e essencial função da liderança é a manipulação da cultura" (1991, p. 317). Neste sentido, e tal como escrevíamos noutro local, pode dizer-se que:

A questão da liderança passa, assim, a fazer parte integrante dos estudos sobre a cultura organizacional tendo vindo, concomitantemente, a dar-se uma deslocação significativa das conceções tradicionais da liderança (ligada aos modelos racionais e burocráticos) para um novo entendimento do papel do líder mais ligado às questões culturais e simbólicas e aos processos de influência (COSTA, 2003, p. 133).

A este propósito se referem também Reto e Lopes que, identificando liderança com influência, apresentam três dimensões essenciais do papel e das funções dos líderes enquanto gestores da cultura e do simbólico organizacional: "A criação de uma visão que permita dotar a empresa de uma identidade; a ancoragem desta visão no sistema de normas e valores maioritariamente partilhados na organização; a personificação da identidade do grupo e da própria visão" (sd, p. 77).

É com base numa conceção deste tipo dos líderes organizacionais que Deal (1992, p. 4) não hesita em apelidar estes "atores cimeiros" da vida das organizações com metáforas como as de "profetas", "poetas", "negociadores" e "encenadores". O líder cultural surge, assim, como aquele que centra a sua ação na criação e na gestão da cultura da organização (manipulando valores, rituais, cerimónias, histórias, heróis, mitos e toda uma série de artefactos simbólicos) de modo a criar nos membros da organização um sentido para a realidade, uma

\footnotetext{
${ }^{3}$ Sobre estas conceções de liderança, veja-se o já citado estudo de Rego (1997, p. 359-418) onde o autor procede a uma análise pormenorizada da temática. Castanheira (2010) apresenta também uma discussão desta temática suportada pelo modelo de enquadramentos organizacionais de Bolman e Deal (2003).
} 
identidade e uma mobilização coletiva para a ação sustentados por determinada visão organizacional. A visão organizacional surge como elemento-chave desta perspetiva: o líder não atua apenas diretamente sobre os processos de decisão, mesmo que seja para envolver os outros nesses processos, o líder vai para além desse envolvimento, procurando criar uma visão que mobilize os membros da organização, os inspire e os motive (OWENS, 1998, p. 217).

A ligação que temos estado a estabelecer entre a visão cultural da liderança (e as chamadas conceções da nova liderança) e a perspetiva da cultura organizacional, não é extensível aos posicionamentos dos vários autores que se situam no quadro desta última perspetiva de análise organizacional. As nossas interpretações reportam-se aqui basicamente a uma conceção mais unitária, consensual, homogénea e manipulável da cultura, presente nos trabalhos de pendor mais gestionário, e que Martin (1992) classifica como a perspetiva integradora da cultura. Para além desta, a autora propôs mais duas perspetivas enquadradoras da temática (enformadas por uma leitura mais sociológica e interpretativa da realidade organizacional): a perspetiva diferenciadora (que faz apelo à existência de diversas subculturas, à falta de consenso geral e à presença dos conflitos no interior das organizações) e a perspetiva fragmentadora (que alerta para os níveis de ambiguidade e de confusão existentes quer na chamada cultura da organização, quer nas suas subculturas).

Estas duas últimas dimensões de análise da cultura apontam-nos, porém, para uma outra visão da liderança que classificámos de visão ambigua da liderança.

\section{VISÃO AMBÍGUA DA LIDERANÇA: O LÍDER POLIÉDRICO}

A conceção das organizações como unidades homogéneas e estáveis, devidamente estruturadas e hierarquizadas, sujeitas a processos de planificação pormenorizados e sequenciais, com objetivos e tecnologias bem definidos, numa adequação mecânica entre meios e fins, dirigidas e controladas segundo uma lógica de coerência e racionalidade, parece estar cada vez mais posta em causa. Em contrapartida, as organizações são, hoje em dia (ou, mais precisamente, a partir do período que alguns apelidam de pós-modernidade), entendidas como organizações flexíveis, instáveis, dependentes dos estados de turbulência do mundo exterior, marcadas por níveis elevados de incerteza, de desarticulação interna e de desordem, sujeitas a processos de reestruturação e de redefinição frequentes das suas estratégias e a cujos atores se reconhece disporem de um papel estratégico no seu desenvolvimento que é marcado por conflitos, poderes e processos de influência dificilmente conciliáveis com a ordem que tradicionalmente lhes era atribuída. 
Esta concetualização das organizações - que corresponde a uma mudança de paradigma nos modos de entender, de estudar e de gerir as organizações tem o seu enquadramento teórico ancorado em diversos desenvolvimentos de que a análise organizacional foi alvo nas últimas duas ou três décadas: estamos a reportar-nos a perspetivas como as da anarquia organizada, dos modelos micropolíticos, da teoria do caos, do neo-institucionalismo, da perspetiva da hipocrisia organizacional... as quais vieram romper, globalmente, com o paradigma da racionalidade técnica caraterizador da história anterior da construção teórica nesta área.

Este quadro de redefinição organizacional levou a que também as conceções sobre a liderança se reequacionassem. Assim, já em meados dos anos 70, Cohen e March (1974, p. 195-203), no âmbito de um estudo que reconhecia, no funcionamento e na gestão das organizações escolares, níveis elevados de ambiguidade, de imprevisibilidade e de incerteza (trabalho intitulado Leadership and Ambiguity), invocavam o grau significativo de ambiguidade presente nos cargos de liderança deste tipo de organizações, apontando quatro tipos de ambiguidade com que se confronta o líder formal: a ambiguidade das intenções, a ambiguidade do poder, a ambiguidade da experiência e a ambiguidade do êxito ${ }^{4}$.

Este conjunto de novos desenvolvimentos sobre o entendimento da liderança nas organizações aponta claramente para uma conceção alternativa às anteriormente apresentadas que Bryman (1996, p. 283-284) classificou como liderança dispersa. Nesta perspetiva, a liderança passa a ser equacionada como uma atividade dispersa que percorre a organização na sua totalidade e não propriamente como um atributo dos líderes formais, nomeadamente do líder heroico (figura tão acarinhada por muita da literatura da especialidade).

São vários os aspetos que abonam em favor da constatação (e até da valorização) da dispersão da liderança nas organizações, designadamente: i) a importância dada à liderança participativa, especialmente quando se invoca como uma das tarefas básicas da liderança levar os outros a serem também eles próprios líderes (autoliderança); ii) a ênfase colocada nas equipas, na valorização e mesmo num certo culto do grupo, com a constituição de equipas de projetos e de equipas autogeridas, centrando o fenómeno da liderança no espaço específico de cada uma das várias equipas; iii) o papel decisivo que cada vez mais se atribui (e se reconhece) às lideranças intermédias e às manifestações daí decorrentes, como sejam os seus territórios mais ou menos bem demarcados, as suas estratégias próprias, os seus espaços de poder e as suas esferas de influência, de modo a que, não raras vezes, deparamos com líderes intermédios que se constituem como

\footnotetext{
${ }^{4}$ Não é a primeira vez que nos reportamos a este estudo de Cohen e March, designadamente a estes quatro tipos de ambiguidade de liderança presente nas organizações escolares (COSTA, 2003; CASTANHEIRA, 2010).
} 
efetivos centros de contrapoder relativamente ao líder formal; iv) a visibilidade que diversos estudos trouxeram aos chamados líderes informais, reconhecendo a proliferação de práticas efetivas de liderança dissipadas pelos vários sectores da organização, reconhecendo-se a existência da função de liderança à margem dos líderes formais; v) a constatação de que os líderes não são grandes heróis do sexo masculino, de que a liderança é diferente da gestão (há líderes que não são gestores e o gestores que não são líderes), de que a autoridade é diferente da liderança, de que a liderança não se situa exclusivamente no topo da estrutura organizacional.

Por conseguinte, e situando-nos nesta perspetiva de análise organizacional, parece, à partida, mais apropriado falar em lideranças do que em liderança, mais nos líderes do que no líder. Ou seja, a visão ambigua da liderança dá-nos conta de um fenómeno disperso, de contornos pouco definidos, presente nos mais diversos níveis e atores da vida organizacional e cuja identificação está marcada e dependente de graus elevados de incerteza, de instabilidade e de irracionalidade que caraterizam as organizações dos nossos dias, quer ao nível global das suas práticas, quer, especificamente, no que diz respeito aos seus processos de direção e gestão.

Nesta perspetiva de ambiguidade da liderança, o gestor surge como um líder poliédrico, ou seja, aquele que se adapta a uma realidade organizacional em permanente mudança e que responde aos constantes desafios e ambiguidades de forma adaptativa. O gestor passa a ser mais um elemento da organização, dotado do poder e da autoridade que lhe é investida pelo cargo, mas que tem a discricionariedade de distribuir (à frente falaremos da liderança distribuida) o grau de poder e de autoridade que entender ser melhor para a persecução dos objetivos organizacionais. Neste sentido, o líder passa a não ser a figura de proa da organização, mas a figura de base que se adapta e molda às circunstâncias, dispersando o seu poder para que a organização sobreviva dentro de um sistema complexo e em permanente mudança.

\section{LIDERANÇA NAS ORGANIZAÇÕES ESCOLARES: ALGUMAS DIMENSÕES BÁSICAS}

As escolas, enquanto organizações, não escapam às investidas do percurso teórico que equacionámos anteriormente. Se, por um lado, reconhecemos à escola alguma especificidade organizacional que a diferencia de outras organizações, também é verdade que a escola depende frequentemente de modelos de análise organizacional e de orientações normativas importados de outros contextos, designadamente do empresarial. Porém, não seria justo ignorar que também a 
análise organizacional em geral recebe cada vez mais influências de muitas das investigações produzidas no campo das organizações educativas. Recordemos, como exemplo, a influência que tem exercido o trabalho de Weick (1976) sobre as escolas como sistemas debilmente articulados na análise de outros contextos não escolares.

Contudo - independentemente de uma certa globalização dos modelos de análise organizacional que hoje percorrem organizações de missão e perfil diversos (empresas, escolas, hospitais, administração pública, sociedades culturais, recreativas, solidárias, assistenciais, organizações políticas, etc.) parece-nos importante apontar para uma certa especificidade das organizações educativas, designadamente em termos da singularidade da sua missão, que é uma missão essencialmente pedagógica e educativa (dirigida a crianças e jovens em desenvolvimento).

Com este pressuposto - o do carácter essencialmente pedagógico das organizações escolares - não é nossa intenção criar uma visão homogénea, consensual e coesa dos estabelecimentos de ensino, até porque são várias as caraterizações da vida escolar que nos dão conta deste tipo de organizações como debilmente articuladas, sujeitas a processos de conflitualidade de interesses e de luta pelo poder, dispondo de práticas ritualizadas, de cerimoniais de fachada e de hipocrisia, ou mesmo de contextos marcados pela anarquia, pela desordem ${ }^{5}$.

Porém, e assumindo-se neste momento uma postura um pouco mais normativa, parece-nos que a escola, classificada como organização pedagógica, assume uma identidade que vai para além da dimensão de instrução e de ensino e mesmo do próprio conceito de educação. González (2003, p. 37-38) afirma que uma escola é uma organização complexa, composta por pessoas e pelas suas interações, na qual se leva a cabo uma tarefa plena de valores e ética que não pode ser realizada de modo mecânico dado que são as interações e os processos de negociação social das pessoas que fazem a escola. Nesta perspetiva, a escola não é só uma organização democrática, mas uma organização onde as práticas da democracia são objetivo da sua ação; não é só uma escola justa, mas uma organização onde há uma pedagogia da justiça; não é só uma organização aprendente (SENGE, 1990), mas um contexto onde se pratica uma pedagogia da aprendizagem; não é só uma escola autónoma, mas, como escrevia Lima (1999), na esteira de Paulo Freire, uma organização de pedagogia da autonomia. Ou seja, os próprios modos de organização e os processos de gestão não

\footnotetext{
${ }^{5}$ Já por diversas vezes nos socorremos destes conceitos para o estudo das organizações escolares, quer em termos de sistematização e enquadramento teórico-conceptual (COSTA, 2003), quer ao nível da análise das práticas, designadamente, a investigação que realizámos sobre os projetos de escola (COSTA, 1997; 2007).
} 
deverão apresentar-se somente enquanto meios para o desenvolvimento da ação pedagógica mas constituírem-se eles próprios como objetos de ação pedagógica.

Por conseguinte, e não obstante termos de reconhecer que outras organizações não escolares não ignoram alguma intenção pedagógica nos seus objetivos, no caso da escola, a vertente pedagógica é o centro de toda a sua ação. Este posicionamento leva-nos, também, em termos de conceção da liderança nas organizações escolares, a equacionar a liderança não só como um meio para o desenvolvimento de uma ação pedagógica nas escolas, mas a conceber a própria liderança como objeto de ação pedagógica. Ou seja, estamos a falar numa liderança educativa e pedagógica.

Vários argumentos têm vindo a ser invocados para esta conceptualização. Assim, Fátima Sanches lembra quer a relação de causalidade que diversos estudos estabeleceram entre liderança pedagógica e escolas excelentes, quer ovalor do conhecimento de conteúdo pedagógico que os docentes adquirem (seja na sua formação inicial, seja nas práticas de ensino) poderem ser invocados como "base potencial essencial para o exercício da governação escolar” (1995, p. 526). O apelo a uma liderança de tipo educativo e pedagógico, e a consequente crítica implacável a outros modos de liderança, surge também como assunto dominante de diversos autores, designadamente daqueles que se situam nas chamadas perspetivas críticas, como é o caso de John Smyth (1994), quando exigem nos contextos escolares aquilo que, na terminologia deste autor, se identifica exatamente com a expressão liderança educativa e pedagógica. A principal mensagem destes estudos vai no sentido da defesa de uma liderança participativa, colaborativa, emancipatória, de interpretação crítica da realidade e da correspondente recusa das visões mecanicistas, hierárquicas, tecnocráticas e instrumentais da liderança, pois, de acordo com as palavras de Smyth, "a ideia de um grupo (os líderes) que exerce hegemonia e dominação sobre outro (os seguidores) é, de certo modo, antieducativa" (1994, p. 221).

A adoção do carácter educativo e pedagógico da liderança escolar Sergiovanni fala-nos mesmo na liderança como pedagogia (1998) - surge assim como uma dimensão importante para a construção de um quadro teórico-conceptual que suporte e enforme o desenvolvimento destes processos cuja presença nas mais diversas práticas das organizações educacionais não pode ser menorizada.

Não sendo essa a tarefa (bem mais grandiosa que o presente trabalho) que assumimos neste momento, gostaríamos, todavia, de sinalizar seis dimensões que, em jeito de pressupostos teórico-conceptuais, nos parece importante ter em conta no estudo sobre o fenómeno da liderança nas organizações escolares: i) distinção entre liderança e gestão; ii) liderança dispersa e distribuída; iii) 
colegialidade docente e liderança; iv) liderança transformacional e inovação; v) liderança pedagógica e resultados escolares; vi) liderança escolar, valores e ética.

\section{DISTINÇÃO ENTRE LIDERANÇA E GESTÃO}

Se do ponto de vista das expectativas (vertente prescritiva) somos tentados a identificar o gestor com o líder, ou melhor, atribuir ao bom gestor a capacidade da liderança, não estamos, todavia, perante uma situação de causalidade linear, nem perante conceitos sinónimos: vários são os líderes (efetivos) em contexto escolar que não exercem funções de gestão organizacional, bem como inúmeros serão os gestores escolares (absorvidos e dependentes das tarefas administrativas e técnicas) que se encontram afastados do exercício efetivo da liderança. Porém, a distinção entre liderança e gestão é uma questão polémica neste campo de estudo.

Autores como Yukl (1989) referem que a diferença essencial entre liderança e gestão se prende com o facto de os líderes influenciarem o compromisso para com a organização, enquanto os gestores agem de acordo com as responsabilidades decorrentes da sua posição e exercem autoridade sobre os subordinados. No entanto, o mesmo autor reconhece que existem opiniões diferentes neste campo, o que, uma vez mais, remete para a dificuldade em definir liderança de modo universalmente aceite. Este autor considera que não há necessidade de distinguir os dois termos e usa-os praticamente como sinónimos ao longo do seu trabalho (YUKL, 1989, p. 4-5). Também Day considera que liderança e gestão são conceitos distintos, mas que são postos em prática pelos gestores escolares requerendo um equilíbrio especial no seu exercício. Para Day, a liderança é, acima de tudo, um processo de construção e manutenção de uma visão, cultura e relações interpessoais, enquanto a gestão prende-se com a coordenação, apoio e monitorização das atividades organizacionais (2003, p. 167). Earley e Weindling defendem que entre liderança e gestão existem algumas diferenças: a liderança tende a ser mais formativa, proactiva e relacionada com a resolução de problemas, estando mais ligada a conceitos como visão, missão e valores, enquanto a gestão tende a estar mais orientada para o planeamento, organização e execução, para o uso dos recursos (2004, p. 5). No entanto, entendem que ambas são essenciais para o sucesso de uma organização e que, na prática, líderes e gestores são quase indistinguíveis. Neste ponto, os autores aproximam-se do ponto de vista de Bush e Middlewood que defendem que a liderança e a gestão devem ter igual ênfase para que uma organização tenha sucesso, operando de modo eficaz e atingindo os seus objetivos, dado que, se é importante que se tenha uma visão clara para que se estabeleça a direção que se pretende que a organização atinja, é igualmente importante assegurar que as 
inovações sejam implementadas de modo eficaz e que as funções quotidianas da escola estejam a ser bem desempenhadas enquanto se procede a mudanças noutros sectores (2005, p. 4).

Zaleznick é outro dos autores mais citados no que toca a esta questão da diferença entre gestão e liderança. Este autor discute os conceitos de liderança e gestão e afirma que as diferenças entre líder e gestor são profundas e têm raízes na própria forma de vida do indivíduo: "os gestores e os líderes são tipos diferentes de pessoas. Diferem na motivação, na sua história pessoal e no modo como pensam e agem" (2004, p. 75). Deste modo, os gestores são vistos por Zaleznick como pessoas cuja atenção se dirige ao modo como as coisas são feitas, enquanto os líderes são pessoas cuja atenção se foca no que os acontecimentos e as decisões significam para os participantes (ibidem, p. 78). No entanto, a distinção entre liderança e gestão mais frequentemente citada é de Bennis e Nanus (1985, p. 21): "os gestores fazem as coisas bem, os líderes fazem as coisas certas". Na mesma esteira segue Earley que afirma que "a liderança tende a ser mais formativa, mais proactiva e mais ligada à resolução de problemas, lidando com coisas como valores, visão e missão, enquanto os gestores tendem a preocupar-se com a execução, planeamento, organização e alocação de recursos, ou 'fazer as coisas acontecer"' (2002, p. 34). No entanto, Earley reconhece que tanto a liderança, como a gestão se poderão sobrepor, sendo essenciais para o sucesso da organização.

Ou seja, se, do ponto de vista concetual, a distinção entre liderança e gestão parece pertinente, concordamos também com os autores que, situando-se numa perspetiva normativa, entendem que conciliar liderança e gestão é fundamental para a melhoria e o desenvolvimento bem-sucedido das organizações.

\section{LIDERANÇA DISPERSA E LIDERANÇA DISTRIBUÍDA}

A liderança constitui-se como um fenómeno disperso que percorre os diversos níveis, sectores e agrupamentos da organização escolar e não propriamente um atributo do líder formal (ou dos líderes formais). O diagnóstico da conexão débil (WEICK, 1976) presente entre as várias estruturas, processos e indivíduos das organizações escolares legitima ainda mais este fenómeno da multiplicação das lideranças de modo que, mais do que de liderança podemos falar de lideranças, mais do que o líder, temos os líderes, dispersos, mas presentes e ativos na difusão das ideias, na definição dos processos e no protagonismo das práticas.

Um dos conceitos de liderança que tem ganho proeminência nos últimos anos é o da liderança distribuída em oposição ao domínio quase absoluto das 
teorias de liderança focadas num só líder (GRONN, 2002, p. 423; MUIJS; HARRIS, 2003, p. 437; WOODS, 2005, p. vi-vii), embora, de acordo com alguns autores (veja-se HARRIS, 2004, p. 13) existam diversas interpretações do conceito. Gronn critica o estado da arte no que se reporta ao estudo da liderança defendendo que é preciso ir além dos dois dualismos "sacrossantos" deste campo - o dualismo líder-seguidores e o liderança-obediência - existindo abordagens que enfatizam o papel dos seguidores e que desvalorizam a importância da obediência no que respeita ao processo de liderança (2002, p. 425).

Da mesma forma, Harris defende que a liderança distribuída poderá preencher um "ponto cego" - áreas em falta na pesquisa sobre a liderança - dado que a maioria dos estudos se foca na liderança centrada num indivíduo só (2004, p. 12). Harris define liderança distribuída como "uma forma de liderança coletiva na qual os professores desenvolvem a sua sabedoria ao trabalhar em conjunto" (ibidem, p. 14). Desta forma, todos os membros da organização poderão, potencialmente, ser líderes (GRONN, 2002, p. 429), abrindo a possibilidade de uma liderança mais coletiva e democrática (MUIJS; HARRIS, 2003, p. 439) e, assim, uma das propriedades da liderança distribuída será a interdependência.

Os líderes, nesta abordagem, dependem de outros membros da organização para desempenhar as suas funções, ou porque as suas funções se sobrepõem ou porque as suas responsabilidades se complementam; por outro lado, a liderança distribuída implica coordenação, quer implícita, quer explícita para o planeamento e organização do tempo e dos recursos, para a padronização dos meios e para a gestão da informação e comunicação (GRONN, 2002, p. 432 433). Para a liderança distribuída o gestor é apenas um membro da organização a quem foi atribuído o estatuto de líder através de um contrato legal, embora a liderança em si não possa ser atribuída desta forma e dependa da vontade dos seguidores (ibidem, p. 442).

Pelo antes exposto, o conceito de liderança distribuída tem significativas implicações no que diz respeito ao estudo da liderança, dado que desafia a noção de que o gestor é o líder, bem como ao modo mais autocrático de dirigir as organizações, pelo reconhecimento da relatividade deste tipo de atuação e da sua desadequação em organizações, como as educativas, onde o envolvimento coletivo nas decisões é fundamental.

\section{COLEGIALIDADE DOCENTE E LIDERANÇA}

O reconhecimento de que o funcionamento da vida escolar deverá estar pautado por procedimentos democráticos parece inquestionável; uma escola alinhada pelos princípios da igualdade de oportunidades, da autonomia, da 
justiça e da equidade pressupõe que a construção e organização dos processos de ensino e aprendizagem ocorram de forma participada e numa lógica de cidadania organizacional; isto significa que a liderança escolar não só não poderá esquecer este pressuposto, mas deverá desenrolar-se no sentido da revitalização da democracia e da participação de todos os implicados nos processos educativos, assumindo assim uma feição emancipadora e facilitadora na capacidade de decisão coletiva.

A questão das culturas docentes, especialmente o fenómeno da colegialidade docente, implica o reconhecimento da liderança enquanto processo que se desenrola inter pares; os discursos cada vez mais acentuados sobre a profissionalidade e a autonomia docentes, os apelos às culturas de colaboração, ao trabalho de coconstrução do currículo, à colegialidade das decisões, à reflexão partilhada sobre a ação, não só potenciam o desenvolvimento de lideranças dispersas, como colocam os líderes perante novos desafios de atuação no sentido de uma liderança colaborativa, colegial e solidária, respeitadora das autonomias individuais e grupais e exercendo-se em conjunto com estas.

Para Woods e Woods, a colegialidade tem como principal vantagem o facto de se aceitar que todos os membros da organização têm a sua área de especialidade que trazem para o conjunto mais alargado, num espaço onde todos sentem que têm uma palavra a dizer, que têm voz no rumo da organização (2006, p. 12). Para além da vertente positiva da colegialidade - tomada de decisão coletiva, designadamente sobre assuntos estratégicos, maior facilidade na sua aceitação e implementação dada a descentralização, ambiente mais propício à construção de relações e à manutenção de uma identidade colegial, já que são todos co-líderes, evitando, até certo ponto, o conflito - Woods e Woods apresentam algumas fraquezas deste tipo de liderança relacionadas com o seu carácter (micro)político, nomeadamente: o facto de a liderança colegial poder consumir muito tempo na tomada de decisão (devido à negociação), de haver um potencial défice de responsabilidade (dada a dispersão da iniciativa e a facilitação) e as diferenças de poder e de estatuto implícitas que subjazem aos processos de negociação na decisão coletiva (2006. p. 18-25).

Assim, seguindo de perto o pensamento de Muijs e Harris (2003, p. 443), a liderança dos professores surge em contextos marcados pelas culturas de colegialidade, constituindo uma das tarefas básicas do professor-líder, precisamente, a de fomentar a colaboração entre os docentes de modo a desenvolver aprendizagens coletivas, o que requer elevadas capacidades de relacionamento interpessoal e tempo para que estes possam refletir, discutir e planear em conjunto a ação educativa. 


\section{LIDERANÇA TRANSFORMACIONAL E INOVAÇÃO}

Com forte ênfase no empowerment, temos a liderança transformacional, um conceito utilizado pela primeira vez por Burns em 1978. De acordo com Leithwood e Jantzi, "todas as abordagens transformacionais enfatizam emoções e valores e partilham o objetivo fundamental de criar a capacidade para o desenvolvimento e níveis de maior compromisso pessoal para com os objetivos organizacionais por parte dos colegas dos líderes" (2005, p. 31). A influência é distribuída ao longo de toda a organização, não estando o poder alojado nos detentores de cargos hierarquicamente superiores, mas sim nos membros que consigam inspirar os colegas para desenvolverem as suas capacidades em prol da organização (ibidem, p. 32).

A liderança transformacional comporta quatro componentes essenciais: a componente carismática, de desenvolvimento de uma visão e de indução do orgulho, do respeito e da confiança; a componente inspiracional, de motivação, de estabelecimento de objetivos e metas elevadas, de modelagem de comportamentos no sentido de atingir as metas estabelecidas; a componente de respeito pelos subordinados no sentido de lhes prestar toda a atenção; e a componente de estimulação intelectual, de desafio, de "espicaçar" os subordinados com novas metas e com novos métodos para as atingir (ANTONAKIS; AVOLIO; SIVASUBRAMANIAN, 2003; AVOLIO et al., 2004; BASS et al., 2003).

O líder transformacional é respeitado pelos seguidores, inspira confiança e é visto como um exemplo a seguir. Este tipo de líder é proactivo e comportase de forma a motivar os seguidores, desafiando-os a superar os seus limites e a procurar soluções criativas e estimulantes para a resolução de problemas. Para além disto, o líder transformacional presta atenção às necessidades de desenvolvimento profissional e de prossecução de objectivos de cada seguidor, agindo por vezes como mentor. O líder transformacional aumenta também o grau de compromisso dos seguidores para com a visão, a missão e os valores organizacionais comuns ao enfatizar a relação entre os esforços dos seguidores e o alcançar das metas organizacionais. O líder transformacional, em suma, é visto como um gestor de sentido, alguém que define a realidade organizacional através de uma visão que reflete a forma como o líder interpreta a missão e os valores nos quais a ação organizacional se deverá basear.

A liderança transformacional tem sido apresentada como uma alternativa à liderança transacional, na medida em que esta última se foca na existência de um sistema de recompensas e de castigos aplicados pelo líder em resultado do cumprimento, ou não, de objetivos contratuais. A liderança transacional difere assim da liderança transformacional, já que, naquela, o líder apenas indica 
quais os comportamentos a adotar e os objetivos a atingir, não influenciando, nem motivando os seguidores para a prossecução das metas desejadas. A liderança transacional baseia-se, então, numa dicotomia clara entre o líder enquanto superior e o seguidor enquanto dependente, numa perspetiva mais de conformidade do que de criatividade face aos desafios e às metas impostas pela realidade organizacional (BARNETT; MCCORMICK, 2004: 407-409; BRYMAN, 1996: 280-281; CASTANHEIRA; COSTA, 2011; DAY, 2003: $164-$ 166; HARRIS, 2003: 16-18; HOPKINS, 2003: 56-57).

Assim, a liderança transformacional surge conotada com os processos de inovação e mudança organizacional, caracterizando-se por ter uma forte componente pessoal na medida em que o líder transformacional motiva os seguidores, introduzindo mudanças nas suas atitudes de modo a inspirá-los para a realização de objetivos suportados por valores e ideais.

\section{LIDERANÇA PEDAGÓGICA E RESULTADOS ESCOLARES}

A importância que a liderança desempenha nos resultados escolares dos alunos tem sido objeto de um acesso debate, com as reformas educacionais contemporâneas a atribuírem um grande relevo à liderança e à gestão eficaz das escolas (DAY; SAMMONS, 2013).

Diversos estudos defendem que uma escola que tenha um ambiente ordeiro e seja bem gerida providencia condições que promovem a aprendizagem, logo, que a liderança seja fator de qualidade das escolas (JACOBSON, 2011; MULFORD; SILLINS, 2011; PONT; NUSCHE; MOORMAN, 2008; ROBINSON; LLOYD; ROWE, 2008; ROBINSON; HOHEPA; LLOYD, 2009; SAMMONS et al., 2011; SCHEERENS, 2012; PASHIARDIS, 2014).

No entanto, existem divergências quanto ao tipo e qualidade da influência que a liderança poderá ter na qualidade das escolas. Diversas metanálises de estudos sobre liderança educacional referem que o impacto da liderança na qualidade das escolas é indireto, enquanto outros estudos referem que a liderança tem impacto direto nos resultados dos alunos e outros, ainda, que a influência é recíproca (DAY; SAMMONS, 2013; GRISSOM; LOEB, 2011; HALLINGER, 2008; HALLINGER; HECK, 1998; JACOBSON, 2011; LEITHWOOD; JANTZI, 2008; MUIJS, 2011; MULFORD; SILINS, 2011; PASHIARDIS, 2014; SAMMONS et al., 2011; ROBINSON; LLOYD; ROWE, 2008).

Estes resultados tão divergentes devem-se, de acordo com Brauckmann e Pashiardis (2011) e Pashiardis (2014), a diferenças na própria conceção do que é a liderança - diferentes estudos ao analisar diferentes tipos de liderança poderão estar a estudar fenómenos completamente diferentes - e à inexistência de um 
paradigma universal para a análise do comportamento organizacional, para além de diferenças metodológicas que poderão afetar os resultados dos estudos e a sua comparabilidade.

No entanto, tal não invalida que a liderança seja considerada um fator determinante no sucesso das escolas (DAY; SAMMONS, 2013), em particular, o realce que tem vindo a ser colocado na chamada liderança pedagógica ("instrucional", na terminologia inglesa) (BUSH, 2011; COSTA; FIGUEIREDO, 2012). Neste sentido, é pela via da centralidade da liderança pedagógica na gestão escolar um tipo de liderança caraterizada por práticas de gestão que têm como objetivo a melhoria do processo de ensino e aprendizagem, enfatizando a aquisição de conhecimentos pelos alunos e respetiva monitorização, dando particular atenção à supervisão do currículo e à eficácia das práticas dos professores - que cada vez mais se reconhece o seu contributo para a melhoria da escola e dos resultados dos alunos.

\section{LIDERANÇA ESCOLAR, VALORES E ÉTICA}

Diversos autores apontam para uma ligação intrínseca e fundamental entre liderança escolar, valores e ética dado o caráter educativo e pedagógico da liderança escolar. Na realidade, se tivermos em conta que a liderança será sempre exercida em função de um grupo, poderemos dizer que a liderança é na sua génese um empreendimento ético, visto que terá que ter em conta os valores assumidos pelo grupo como sendo os valores a seguir (BRANSON; GROSS, 2014, p.1-3; BRANSON, 2014, p. 440). De facto, num mundo progressivamente mais complexo e diverso, os gestores escolares devem desenvolver, apoiar e liderar escolas cada vez mais diversas, tolerantes e democráticas (SHAPIRO; STEFKOVICH, 2005, p. 4).

A adoção de lógicas de mercado e de negócio (com foco em conceitos como eficiência, consumo, vantagens competitivas, criação de valor acrescentado) na educação, sem ter em conta o caráter específico da mesma, levanta questões éticas (BOTTERY, 2014, p. 85). As decisões dos gestores escolares tendo em conta princípios éticos levam muitas vezes ao desencadear de conflitos dado que, em torno da defesa dos melhores interesses dos alunos, giram conceitos como códigos de conduta profissional, padrões de desempenho, ética profissional, ética da comunidade e ética pessoal (SHAPIRO; STEFKOVICH, 2005).

Assim sendo, muitas vezes, a tomada de decisão de um líder escolar encontra-se alicerçada num frágil equilíbrio entre aquilo que é considerado como ético e válido por certos grupos da comunidade e aquilo que é exigido por padrões de desempenho profissional (BATES, 2009, p. 162; SHAPIRO, STEFKOVICH; 
GUTIERREZ, 2014, p. 210). Por exemplo, a pressão pela prestação de contas leva a que também possam existir conflitos entre a ética focada na justiça social e o foco nos resultados escolares dos alunos (MCNAE, 2014, p.106), situação que pressionou o nascimento de novos padrões para a administração escolar que tenham em conta princípios éticos e de justiça social (GROSS; SHAPIRO, 2014, p. 352-369). Perante um sistema em que os resultados escolares são usados como um dos fatores determinante no "julgamento" público de uma escola, como é o caso dos rankings escolares (CASTANHEIRA, 2013), os diretores têm que decidir se dão as mesmas condições a todos os alunos, se focam mais recursos nos alunos que terão hipoteticamente melhores hipóteses de sucesso nos exames ou se, pelo contrário, se focam nos que terão mais dificuldades. Estas decisões, de natureza essencialmente ética, levantam dificuldades e conflitos num contexto de pós-estado social em que se assiste a uma, cada vez maior, competição por recursos escassos e na qual os "bons alunos" (aqueles com os quais se obterá melhores resultados com menores recursos) são cada vez mais vistos como um bem essencial (ANDERSON et al., 2013; HEILIG; NICHOLS, 2013).

Por conseguinte, as decisões escolares e os consequentes processos de gestão e liderança supõem a complexa opção por valores, cuja dimensão ética se encontra sempre e necessariamente presente. Neste contexto, o líder necessita de estar institucionalmente ancorado num quadro de valores e padrões de desempenho devidamente refletidos e coletivamente sustentados.

\section{CONSIDERAÇÕES FINAIS}

O reconhecimento da importância dos processos de liderança no funcionamento e na gestão das organizações escolares continua, como referíamos no início deste trabalho, na ordem do dia. O quadro político da progressiva autonomia e responsabilização dos estabelecimentos de ensino dá novo alento a esta questão colocando os líderes escolares no centro estratégico de um desenvolvimento organizacional que se pretende coeso, eficaz e de qualidade (NÓVOA, 1992, p. 26). Isto significa continuar a manter em lugar estratégico das agendas das políticas educativas (globais e locais) programas de valorização e reconhecimento, de seleção e recrutamento adequados, de avaliação e, naturalmente, de formação qualificada dos líderes escolares - dando maior atenção a questões como as da definição das dimensões do seu desempenho (COSTA; FIGUEIREDO, 2013).

Se num quadro de formação dos gestores escolares não nos parece ser de desprezar dimensões técnicas e instrumentais dos processos de gestão, afigurase-nos, contudo, claro que, no desenvolvimento destes programas de capacitação, 
a vertente educativa e pedagógica da liderança — já que o líder é um educador (STARRAT, 1993, p. 148) - deve sobrepor-se às orientações administrativas, eficientistas e hierárquicas, as quais, como realçámos ao longo do texto, estão longe das características das organizações contemporâneas, em geral, e da especificidade da escola como organização educativa, em particular.

Para além destas considerações de pendor mais normativo, entendemos que a abordagem aqui apresentada poderá contribuir para o desenvolvimento de investigações multivariadas e multiparadigmáticas sobre as práticas de liderança e gestão nas escolas já que procurámos acentuar a importância de se ter em conta um quadro de referência da análise organizacional multifacetado que responda à complexidade quer da problemática quer das organizações educativas em questão.

\section{REFERENNCIAS}

ANDERSON, G. et al. Policy, equity, and diversity in global context. Educational leadership after the Welfare State. In: TILLMAN, L.; SCHEURICH, J. J. (Eds.). Handbook of research on educational leadership for equity and diversity. London: Routledge, 2013.

ANTONAKIS, J.; AVOLIO, B. J.; SIVASUBRAmAniAM, N. Context and leadership: an examination of the nine-factor full-range leadership theory using the Multifactor Leadership Questionnaire. The Leadership Quarterly, n. 14, p. 261-295, 2003.

AVOLIO, B. J. et al. Transformational leadership and organizational commitment: mediating role of psychological empowerment and moderating role of structural distance. Journal of Organizational Behavior, n. 25, p. 951-968, 2004.

BARNETT, K.; MCCORMICK, J. Leadership and individual principal-teacher relationships in schools. Educational Administration Quarterly, n. 40, p. 406434, 2004.

BASS, B. M. Leadership and performance beyond expectations. New York: Free Press, 1985.

BASS, B. M. et al. Predicting nit performance by assessing transformational and transactional leadership. Journal of Applied Psychology, n. 88, p. 207-218, 2003. 
BATES, R. The political economy of the emotions: individualism, culture and markets, and the administration of the self in education. In: SAMIER, E.; SCHMIDT, M. Emotional Dimensions of Educational Administration and Leadership. London: Routledge, 2009.

BENNIS, W.; NANUS, B. Leaders. The strategies for taking charge. New York: Harper and Row, 1985.

BOLMAN, L. G.; DEAL, T. E. Reframing Organizations. Artistry, choice and leadership. San Francisco: Jossey-Bass, 2003.

BOT'TERY, M. Leadership, sustainability, and ethics. In: BRANSON, C.; GROSS, S. J. Handbook of ethical educational leadership. London: Routledge, 2014.

BRANSON, C. Conclusion: if it isn't ethical, it isn't leadership. In: BRANSON, C.; GROSS, S. J. Handbook of ethical educational leadership. London: Routledge, 2014.

BRANSON, C.; GROSS, S. J. Introduction. In: BRANSON, C.; GROSS, S. J. (Eds.). Handbook of ethical educational leadership. London: Routledge, 2014.

BRAUCKMANN, S.; PASHIARDIS, P. A validation study of the leadership styles of a holistic leadership theoretical framework. International Journal of Educational Management, v. 25, n. 1, p. 11-32, 2011, DOI: 10.1108/09513541111100099.

BRYMAN, A. Leadership in organizations. In: CLEGG, S. R.; HARDY, C.; NORD, W.R. (Eds.). Handbook of organization studies. London: Sage, p. 276-292, 1996.

BURNS, J. M. Leadership. New York: Harper \& Row, 1978.

BUSH, T. Theories of educational Leadership and Management. London: Sage, 2001.

BUSH, T.; COLEMAN, M. Leadership and strategic management in education. London: Paul Chapman Publishing, 2000.

BUSH, T.; MIDDLEWOOD, D. Leading and managing people in education. London: Sage, 2005.

CASTANHEIRA, P. Liderança e gestão das escolas em Portugal: o quotidiano do presidente de conselho executivo. Aveiro: Universidade de Aveiro, 2010. 
A avaliação de escolas como fator de competição: uma tendência futura? In: VENTURA, A.; COSTA, J.A.; NETO-MENDES, A. (Org.). Escolas, Competição e Colaboração: que perspetivas? Atas do VII Simpósio de Organização e Gestão Escolar. Aveiro: Universidade de Aveiro, 2013.

Líderes escolares e qualidade educativa: será que a lideranca faz a diferença? In FIALHO, I., VERDASCA, J., CID, MARILIA \& FAVINHA, M. (Org.). Políticas educativas, eficácia e melhoria das escolas. Évora: CIEPUE, 2014.

CASTANHEIRA, P.; COSTA, J. A. In search of transformational leadership: a (meta) analysis focused on the Portuguese reality. Procedia Social and Behavioral Sciences, v. 15, p. 2012-2015, 2011.

CHIAVENATO, I. Introdução à teoria geral da administração. São Paulo: McGraw-Hill do Brasil, 1983.

COHEN, M. D. \& MARCH, J. G. Leadership and ambiguity: the american college president. New York: McGraw-Hill, 1974.

COSTA, J. A. O projecto educativo da escola e as políticas educativas locais: discursos e práticas. Aveiro, Universidade de Aveiro, 1997.

Liderança nas organizações: revisitando teorias organizacionais num olhar cruzado sobre as escolas. In: Costa, J. A.; Neto-Mendes , A.; Ventura, A. (Org.s). Liderança e estratégia nas organizações escolares. Aveiro: Ed. Universidade de Aveiro, pp. 15-33, 2000.

Imagens organizacionais da escola. Porto: Edições ASA, 2003.

Projetos em educação. Contributos de análise organizacional. Aveiro, Editorial da Universidade de Aveiro, 2007.

COSTA, J. A; FIGUEIREDO, S. Liderança instrucional e currículo: uma análise focada nas escolas do ensino secundário. In: Paraíso, M; Vilela, R.; Sales, S. (Orgs.). Desafios Contemporâneos sobre Currículo e Escola Básica. Curitiba: Editora CRV, pp. 99-112, 2012.

Quadros de referência para o desempenho dos líderes escolares. Revista Ensaio: Avaliação e Políticas Públicas em Educação, v. 21, n. 79, p. 183-202, 2013. 
DAY, C. Successful leadership in the twenty-first century. In: HARRIS, A. et al. (Eds.), Effective leadership for school improvement. London: Routledge Falmer, pp.157-179, 2003.

DAY, C.; SAMMONS, P. Successful leadership: a review of the international literature. CfBT Education Trust, 2013. Disponível em: < http://www.cfbt.com/ en-GB/Research/Research-library/2013/r-successful-leadership-2013.pdf> . Acesso em: 3 jan. 2015.

DAY, C. et al. Research into the impact of school leadership on pupil outcomes: Policy and research contexts. School leadership \& management: formerly school organisation, v. 28, n. 1, p. 5-25, 2008, DOI: 10.1080/13632430701800045.

DEAL, T. Leadership in a world of change. In: THOMSON, S. D. (Ed.). School leadership: a blueprint for change. Newbury Park: Corwin Press, p. 1-7, 1992.

DEAL, T.; KENNEDY, A. Corporate cultures: the rites and rituals of corporate life. London: Penguin Books, 1988.

EARLEY, P. Understanding leadership issues. In: BARZANÒ, G.; CLÍMACO, M.; JONES, J. (Eds.). School management and leadership. A comparative approach in Italy, Catalonia, England and Portugal. Roma: Anicia, p. 33-41, 2002.

EARLEY, P.; WEINDLING, D. Understanding school leadership. London: Paul Chapman Publishing, 2004.

EVERARD, K. B.; MORRIS, G.; WILSON, I. Effective school management. London: Paul Chapman, 2004.

FIEDLER, F. E. Situational control and a dynamic theory of leadership. In: PUG, D. S. (Ed.). Organization Theory. Selected Readings. London, Penguin Books, pp. 417-438, 1990.

GARDNER, J. W. The nature of leadership. In: FULLAN, M. (Ed.). The JosseyBass Reader on Educational Leadership. San Francisco: Jossey-Bass, p. 17-26, 2007.

GONZÁLEZ, M. T. Las organizaciones escolares: dimensiones y características. In: GONZÁLEZ, M. T. (Ed.). Organización y Gestión de Centros Escolares. Dimensiones y procesos, Madrid: Pearson Educación, p. 25-40, 2003. 
GRISSOM, J. A.; LOEB, S. (2011). Triangulating Principal Effectiveness: How perspectives of parents, teachers and assistant principals identify the central importance of managerial skills. American Educational Research Journal, v. XX, n. X, p. 1-33, 2011, DOI: 10.3102/0002831211402663.

GRONN, P. Distributed leadership as a unit of analysis. The Leadership Quarterly, n. 13, p. 423-451, 2002.

GROSS, S. J.; SHAPIRO, J. P. Ethical responses to educational policies. In: BRANSON, C.; GROSS, S. J. Handbook of Ethical Educational Leadership. London: Routledge, 2014.

HALLINGER, P. Methodologies for studying school leadership: a review of 25 years of research using the Principal Instructional Management Rating Scale. In: Anual Meeting of the American Educational Research Association. New York: AERA, 2008.

HALLINGER, P.; HECK, R. H. Exploring the principal's contribution to school effectiveness 1980-1995. School Effectiveness and School Improvement, n. 9, p. 157-191, 1998.

HARRIS, A. The changing context of leadership: research, theory and practice. In HARRIS, A. et al. (Eds.), Effective Leadership for School Improvement. London: Routledge Falmer, p. 9-25, 2003.

Distributed leadership and school improvement. Leading or misleading? Educational Management Administration \& Leadership, n. 32, p. 11-24, 2004.

HARRIS, A.; CHAPMAN, C. Democratic School Leadership for School Improvement in Challenging Contexts. International Electronic Journal for Leadership in Learning, v. 6, n. 9, 2002.

HEILIG, J. V.; NICHOLS, S. A quandary for school leaders. Equity, high-stakes and accountability. In: TILLMAN, L.; SCHEURICH, J. J. (Eds.). Handbook of Research on Educational Leadership for Equity and Diversity. London: Routledge, 2013.

HOPKINS, D. Instructional leadership and school improvement. In: HARRIS, A. et al. (Eds.), Effective Leadership for School Improvement. London: Routledge Falmer, p. 9-25, 2003. 
HOUSE, R. J. A 1976 theory of charismatic leadership. In: HUNT, J. G.; LARSON, L. L. (Eds.). Leadership: the Cutting Edge. Carbondale: Southern Illinois University Press, p. 189-207, 1977.

JACOBSON, S. Leadership effects on student achievement and sustained school success. International Journal of Educational Management, v. 25, n. 1, p. 3344, 2011, DOI: 10.1108/09513541111100107.

LAWRENCE, P. R.; LORSCH, J. W. Developing Organizations: Diagnosis and Action. Reading: Addison-Wesley, 1969.

LEITHWOOD, K.; JANTZI, D. Transformational leadership. In DAVIES, B. (Ed.), The Essentials of School Leadership, pp. 31-43. London: Paul Chapman Publishing, 2005.

Linking leadership to student learning: the contributions of leader efficacy. Educational Administration Quarterly, v. 44, n. 4, 2008.

LEITHWOOD, K. et al. Seven Strong Claims about Successful School Leadership. Nottingham: National College for School Leadership, 2006.

LIMA, L. Autonomia da pedagogia da autonomia. Revista Inovação, n. 12, p. 65-84, 1999.

MARTIN, J. Cultures in Organizations. New York: Oxford University Press, 1992.

MCNAE, R. Seeking social justice. In: BRANSON, C.; GROSS, S. J. (Eds.). Handbook of Ethical Educational Leadership. London: Routledge, 2014.

MUIJS, D. Leadership and organisational performance: from research to prescription? International Journal of Educational Management, v. 25, n. 1, p. 45-60, 2011. DOI: 10.1108/09513541111100116.

MUIJS, D.; HARRIS, A. Teacher leadership -improvement through empowerment? An overview of the literature. Educational Management \& Administration, v. 31, n. 4, p. 437-448, 2003.

MULFORD, B.; SILINS, H. Revised models and conceptualisation of successful school principalship for improved student outcomes. International Journal of Educational Management, v. 25, n. 1, p. 61-82, 2011. DOI: 10.1108/09513541111100125. 
NÓVOA, A. Para uma análise das instituições escolares. In: NÓVOA, A. (Coord.). As Organizações Escolares em Análise. Lisboa: Pub. Dom Quixote, p. 13-43, 1992.

OWENS, R. Organizational Behavior in Education. Boston: Allyn and Bacon, 1998.

PASHIARDIS, P. (Ed.) Modeling School Leadership Across Europe. In search of new frontiers. Dordrecht: Springer, 2014.

PETERS, T. J.; WATERMAN Jr., R. H. In Search of Excellence (Na Senda da Excelência). Lisboa: Publicações Dom Quixote, 1987.

PONT, B.; NUSCHE, D.; MOORMAN, H. Improving School Leadership. Volume 1: Policy and Practice. Paris: OCDE, 2008.

REGO, A. Liderança nas Organizações: Teoria e Prática. Aveiro: Universidade de Aveiro, 1997.

RETO, L.; LOPES, A. Liderança e Carisma: O Exercício do Poder nas Organizações. Lisboa: Editorial Minerva, s.d.

ROBINSON, V.; HOHEP, M.; LLOYD, C. School Leadership and Student Outcomes: Identifying what works and why. Best evidence synthesis iteration. Auckland: New Zealand Ministry of Education, 2009.

ROBINSON, V.; LLOYD, C.; ROWE, K. The impact of leadership on student outcomes: an analysis of the differential effects of leadership types. Educational Administration Quarterly, v. 44, n. 5, p. 635-674, 2008.

ROST, J. Leadership for the Twenty-First Century. New York: Praeger, 1991.

SÁEZ CARRERAS, J. La Construccion de la Educacion (entre la tecnología y la crítica). Murcia: I.C.E. Universidad de Murcia, 1989.

SAMMONS, P. et al. Exploring the impact of school leadership on pupil outcomes. International Journal of Educational Management, v. 25, n. 1, p. 83-101, 2011. DOI: 10.1108/09513541111100134.

SANCHES, F. Liderança assistida por pares: articulação entre conhecimento experiencial e conhecimento teórico. In: ESTRELA, A. et al. (Eds.). A Escola um Objecto de Estudo. Actas do V Colóquio Nacional da Secção Portuguesa da AIPELF/AFIRSE. Universidade Lisboa: AFIRSE Portugaise/FPCE, p. 523544, 1995. 
SCHEERENS, J. (Ed.). School Leadership Effects Revisited. Review and Meta-Analysis of Empirical Studies. Dordrecht: Springer, 2012.

SCHEIN, E. H. Organizational Culture and Leadership: A Dynamic View. San Francisco: Jossey-Bass Publishers, 1991.

SENGE, P. The Fifth Discipline. The Art and the Practice of the Learning Organization. London: Century Business, 1990.

SERGIOVANNI, T. Leadership as a pedagogy, capital development and school effectiveness. International Journal of Leadership in Education, v. 1, n. 1, p. 37-46, 1998.

SHAPIRO, J. P.; STEFKOVICH, J. Ethical Leadership and Decision Making in Education. Applying Theoretical Perspectives to Complex Dilemmas. London: Lawrence Erlbaum Associates, 2005.

SHAPIRO, J. P.; STEFKOVICH, J. A.; GUTIERREZ, K. J. Ethical Decision Making. In: BRANSON, C.; GROSS, S. J. (Eds.). Handbook of Ethical Educational Leadership. London: Routledge, 2014.

SMYTH, J. Una concepción 'pedagógica' y 'educativa' del liderazgo escolar. In: ESCUDERO, J. M.; GONZÁLEZ, M. T. Profesores Y Escuela: ¿Hacia una Reconversión de los Centros y la Función Docente? Madrid: Ediciones Pedagógicas, p. 221-250, 1994.

SPILLANE, J. P.; HALVERSON, R.; DIAMOND, J. B. Toward a Theory of Leadership Practice: a distributed perspective (working paper). Evanston: Institute for Policy Research, 1999.

STARRAT, R. (1993). The Drama of Leadership. London: The Falmer Press, 1993.

TAYLOR, F. W. Princípios de Administração Científica. São Paulo: Atlas ( $8^{a}$ ed.), 1990.

TEIXEIRA, S. Gestão das Organizações. Lisboa: McGraw-Hill, 1998.

WEICK, K. E. Educational organizations as loosely coupled systems. Administrative Science Quarterly, v. 21, n. 1, p. 1-19, 1976.

WOODS, P. Democratic Leadership in Education. London: Paul Chapman, 2005. 
YUKL, G. A. Leadership in Organizations. Englewood Cliffs: Prentice-Hall, 1989.

JORGE ADELINO COSTA é doutor em Ciências da Educação e professor catedrático da Universidade de Aveiro, Portugal.Email: jcosta@ua.pt

PATRÍCIA CASTANHEIRA é doutora em Ciências da Educação e investigadora do Centro de Investigação em Educação do Departamento de Educação da Universidade de Brighton, Inglaterra. E-mail: p.castanheira@brighton.ac.uk

Recebido em fevereiro de 2015

Aprovado em março de 2015 